\title{
Review Papers for Journal of Risk and Financial Management (JRFM)
}

\author{
Michael McAleer 1,2,3,4,5 (D) \\ 1 Department of Finance, Asia University, Taichung 41354, Taiwan; michael.mcaleer@gmail.com \\ 2 Discipline of Business Analytics, University of Sydney Business School, Darlington 2006, Australia \\ 3 Econometric Institute, Erasmus School of Economics, Erasmus University Rotterdam, 3062 PA Rotterdam, \\ The Netherlands \\ 4 Department of Economic Analysis and ICAE, Complutense University of Madrid, 28040 Madrid, Spain \\ 5 Institute of Advanced Sciences, Yokohama National University, Kanagawa 240-8501, Japan
}

Received: 14 August 2020; Accepted: 17 August 2020; Published: 18 August 2020

\begin{abstract}
This paper evaluates an editorial and seven invaluable and interesting review papers for the Journal of Risk and Financial Management (JRFM). The topics covered include the rising complexity of bank regulatory capital requirements from global guidelines to their United States (US) implementation, connections among big data, computational science, economics, finance, marketing, management and psychology, factors, outcome, and the solutions of supply chain finance, with a review and future directions, time-varying price-volume relationship, adaptive market efficiency, and a survey of the empirical literature, improved covariance matrix estimation for portfolio risk measurement, stock investment and excess returns, with a critical review in the light of the efficient market hypothesis, and a cross section analysis of country equity returns, and a review of the empirical literature.
\end{abstract}

Keywords: bank regulatory capital requirements; big data; computational science; economics; finance; marketing; management; psychology; supply chain finance; price-volume relationship; adaptive market efficiency; covariance matrix estimation; portfolio risk measurement; stock investment; excess returns; efficient market hypothesis; country equity returns

\section{Introduction}

The Journal of Risk and Financial Management (JRFM) was inaugurated in 2008, and has continued to be published successfully, with Volume 13 being published in 2020. Since the journal was established, JRFM has published in excess of 350 topical and interesting theoretical and empirical papers in financial economics, financial econometrics, empirical finance, banking, finance, mathematical finance, statistical finance, accounting, decision sciences, information management, tourism economics and finance, international rankings of journals in financial economics, and bibliometric rankings of journals in cognate disciplines.

Papers published in the journal range from novel technical and theoretical papers to innovative empirical contributions. The journal/Special Issue wishes to encourage critical review papers on topical subjects in any of the topics mentioned above, in financial economics and in cognate disciplines.

The number of papers with more than 5000 views and/or downloads continues to increase, and stands at 9 at present. The most highly viewed paper garnered almost 14,000 views and well over 11,000 downloads, and the second most highly viewed paper had than 8000 views and around 5500 downloads. This is testimony to the excellent papers that are being submitted to the journal, and the outstanding efforts of all staff associated with the journal.

The Special Issue on "Review Papers for Journal of Risk and Financial Management (JRFM)" consists of 8 interesting and informative critical reviews of novel technical, innovative theoretical, and 
new empirical contributions. The following section presents each of the eight papers, and discusses their significant contributions.

\section{Discussion of the Review Papers}

After the Editorial Note, the remaining seven papers are presented in chronological order.

The editorial by McAleer (2018) considers topical issues that have covered, among many others, risk measures, basis risk, default risk, competing risk, downside risk, upside risk, equity risk, risk calibration, optimal hedging, quadratic hedging, life insurance, reinsurance, financial distress, mergers and acquisitions, stock market integration, forecasting dispersion, stock market crashes, corporate risk and creditworthiness, corporate governance, sensitivity analysis, conserving capital, capital regulation, gammas and deltas, spot and futures markets, financial derivatives, exchange traded funds, generating latent variables, arbitrage, trading strategies, international diversification, domestic diversification, publicly traded companies, Bayesian models, and option pricing.

Moreover, the editorial describes interesting topics that include asymmetry and leverage, implied volatility, local volatility, conditional volatility, stochastic volatility, realized volatility, long memory volatility, collapsing bubbles, mean reversion, quantile regressions, factor analysis, fossil fuels, fertilizers, technical efficiency, nonparametric analysis, entropy, oscillation, default models, executive compensation, portfolio optimization, stochastic dominance, higher-order stochastic dominance, equilibria, stochastic control, finite mixture models, interest rate derivatives, exchange rates, collateralized derivative trading, value-at-risk, conditional value-at-risk, expected shortfall, cross listings, Basel accord, heavy tails, skewness, and higher moments. Furthermore, other challenging topics that have been covered include network analysis, inflation, speculation, expectations, stress testing, credit default swaps, vine copulas, property portfolios, social capital, structured finance, credit scoring, fuzzy support vectors, board structures, firm performance, mortgages, neural networks, integration, fractional integration, cointegration, high frequency, ultrahigh frequency, cloud migration, insolvency, bankruptcies, crypto-currencies, safety evaluation, trade openness, emerging economies, sustainability, foreclosures, experimental evidence, innovations, simulations, text mining, learning, big data, computational science, marketing, management, psychology, contagion, and natural disasters.

The Editor-in-Chief and editorial staff of JRFM at MDPI look forward to working with potential authors of review papers, for which the editorial process will be handled efficiently and in a timely manner.

The invaluable paper by Chang et al. (2018) provides a review of the literature that connects Big Data, Computational Science, Economics, Finance, Marketing, Management, and Psychology, and discusses research issues that are related to the various disciplines. Academics could develop theoretical models and subsequent econometric and statistical models to estimate the parameters in the associated models, as well as conduct a simulation to examine whether the estimators in their theories on estimation and hypothesis testing have good size and high power. Thereafter, academics and practitioners could apply theory to analyze some interesting issues in the seven disciplines and cognate areas.

The interesting paper by Barth and Miller (2018) notes that, after the Latin American Debt Crisis of 1982, the official response worldwide turned to minimum capital standards to promote stable banking systems. Despite their existence, however, such standards have still not prevented periodic disruptions in the banking sectors of various countries. After the 2007-2009 crisis, bank capital requirements have, in some cases, increased, and overall have become even more complex. This paper reviews how:

1. Basel-style capital adequacy guidelines have evolved, becoming higher in some cases and overall more complex;

2. the United States (US) implementation of these guidelines has contributed to regulatory complexity, even when omitting other bank capital regulations that are specific to the US;

3. the US regulatory measures still do not provide equally valuable information about whether a bank is adequately capitalized. 
The informative paper by Marak and Pillai (2019) observes that, in the current highly competitive and fast-changing business environment, in which the optimization of all resources matters, creating an efficient supply chain is crucial. Earlier studies on supply chains have focused on aligning product/services and information flows, while neglecting the financial aspects. Due to this, in recent times, importance has been given to align financial flows with the other components of the supply chain. The interest in supply chain finance rose after the financial crisis, when the bank loans declined considerably, as the need for better management and the optimization of working capital became obvious.

The paper reviews the articles on supply chain finance based on three themes-factors, outcomes, and solutions-while at the same time, providing directions for future research on supply chain finance. This article is unique, as it investigates the factors affecting supply chains, according to the existing literature. It also sheds light on the outcome of the supply chain, without limiting the discussion only to the benefits. Further, it addresses the question: what are the solutions constituting supply chain finance?

Sun et al. (2019) evaluate that the notable literature on portfolio selection and risk measurement has considerably advanced in recent years. The aim of the present paper is to trace the development of the literature and identify areas that require further research. This paper provides a literature review of the characteristics of financial data, commonly used models of portfolio selection, and portfolio risk measurement. In the summary of the characteristics of financial data, we summarize the literature on fat tail and the dependence characteristic of financial data.

In the portfolio selection model part, we cover three models: mean-variance model, global minimum variance (GMV) model and factor model. In the portfolio risk measurement part, we first classify risk measurement methods into two categories: moment-based risk measurement and moment-based and quantile-based risk measurement. Moment-based risk measurement includes time-varying covariance matrix and shrinkage estimation, while moment-based and quantile-based risk measurement includes semi-variance, VaR and CVaR.

In an informative paper, Ying et al. (2019) examine the expansion of investment strategies and capital markets as altering the significance and empirical rationality of the efficient market hypothesis. The vitality of capital markets is essential for efficiency research. The authors explore here the development and contemporary status of the efficient market hypothesis, by emphasizing anomaly/excess returns. Investors often fail to get excess returns; however, thus far, market anomalies have been witnessed, and stock prices have diverged from their intrinsic value.

The paper presents an analysis of anomaly returns in the presence of the theory of the efficient market. Moreover, the market efficiency progression is reviewed, and its present status is explored. Finally, the authors provide enough evidence of a data snooping issue, which violates and challenges the existing proof, and creates room for replication studies in modern finance.

Patil and Rastogi (2019) conduct an informative review of the literature on the price-volume relationship and its relation to the implications of the adaptive market hypothesis. The literature on market efficiency is classified as efficient market hypothesis (EMH) studies or adaptive market hypothesis $(\mathrm{AMH})$ studies. Under each class, studies are categorized, either as return predictability studies or price-volume relationship studies. Finally, the review in each category is analyzed based on the methodology used. The review shows that the literature on return predictability and price-volume relationship in classical EMH approach is extensive, while studies in return predictability in the AMH approach have gained increased attention in the last decade.

However, the studies in price-volume relationship under adaptive approach are limited, and there is a scope for studies in this area. Authors did not find any literature review on time-varying price-volume relationship. Authors find that there is a scope to study the nonlinear cross-correlation between price and volume using detrended fluctuation analysis (DFA)-detrended cross-correlational analysis (DXA) in the AMH domain. Furthermore, it would be interesting to investigate whether the 
same cross-correlation holds across different measures of stock indices, within a country and across different time scales.

Zaremba (2019) provides and interesting review of the last three decades, that have brought mounting evidence regarding the cross-sectional predictability of country equity returns. The studies not only documented country-level counterparts of well-established stock-level anomalies, such as size, value, or momentum, but also demonstrated some unique return-predicting signals, such as fund flows or political regimes. Nonetheless, the different studies vary remarkably in terms of their dataset and methods employed.

The authors provide a comprehensive review of the current literature on the cross-section of country equity returns. We focus on three particular aspects of the asset pricing literature. First, we study the choice of dataset and sample preparation methods. Second, we survey different aspects of the methodological approaches. Last but not least, we review the country-level equity anomalies discovered so far. The discussed cross-sectional return patterns not only provide new insights into international asset pricing, but can also be potentially translated into effective country allocation strategies.

Funding: For financial support, the author wishes to acknowledge the Australian Research Council and the Ministry of Science and Technology (MOST), Taiwan.

Conflicts of Interest: The author declares no conflict of interest.

\section{References}

Barth, James R., and Stephen Matteo Miller. 2018. On the Rising Complexity of Bank Regulatory Capital Requirements: From Global Guidelines to their United States (US) Implementation. Journal of Risk and Financial Management 11: 77. [CrossRef]

Chang, Chia-Lin, Michael McAleer, and Wing-Keung Wong. 2018. Big Data, Computational Science, Economics, Finance, Marketing, Management, and Psychology: Connections. Journal of Risk and Financial Management 11: 15. [CrossRef]

Marak, Zericho R., and Deepa Pillai. 2019. Factors, Outcome, and the Solutions of Supply Chain Finance: Review and the Future Directions. Journal of Risk and Financial Management 11: 3. [CrossRef]

McAleer, Michael. 2018. Editorial Note: Review Papers for Journal of Risk and Financial Management (JRFM). Journal of Risk and Financial Management 11: 20. [CrossRef]

Patil, Ashok Chanabasangouda, and Shailesh Rastogi. 2019. Time-Varying Price-Volume Relationship and Adaptive Market Efficiency: A Survey of the Empirical Literature. Journal of Risk and Financial Management 12: 105. [CrossRef]

Sun, Ruili, Tiefeng Ma, Shuangzhe Liu, and Milind Sathye. 2019. Improved Covariance Matrix Estimation for Portfolio Risk Measurement: A Review. Journal of Risk and Financial Management 12: 48. [CrossRef]

Ying, Qianwei, Tahir Yousaf, Qurat ul Ain, Yasmeen Akhtar, and Muhammad Shahid Rasheed. 2019. Stock Investment and Excess Returns: A Critical Review in the Light of the Efficient Market Hypothesis. Journal of Risk and Financial Management 12: 97. [CrossRef]

Zaremba, Adam. 2019. The Cross Section of Country Equity Returns: A Review of Empirical Literature. Journal of Risk and Financial Management 12: 165. [CrossRef]

(C) 2020 by the author. Licensee MDPI, Basel, Switzerland. This article is an open access article distributed under the terms and conditions of the Creative Commons Attribution (CC BY) license (http://creativecommons.org/licenses/by/4.0/). 